\title{
Effects of reactivation context on glucose modulation of reactivated memories
}

\author{
WARD A. RODRIGUEZ \\ California State University, Hayward, Califormia \\ and \\ C. ARLENE HORNE, BRADLEY H. HAAS, and JAMES L. PADILLA \\ New Mexico Highlands University, Las Vegas, New Mexico
}

\begin{abstract}
We used a passive avoidance to active avoidance negative transfer design to investigate the contextand dose-dependent effects of glucose on reactivated memories in rats. Memory reactivation consisted of reexposing rats $24 \mathrm{~h}$ after passive avoidance training to contextual and learning cues that had been present during training. Immediate postreactivation glucose administration was followed $24 \mathrm{~h}$ later by active avoidance (discrimination reversal) training. The memory reactivation treatments were designed to reactivate the rats' memories with different degrees of fidelity. We found a direct relationship between the effectiveness of the memory reactivation treatment and the further enhancement of memory by postreactivation administration of glucose $(100 \mathrm{mg} / \mathrm{kg})$. In another experiment, we found that changes in memory strengthening or retrievability were both dose (glucose: 100,320 , or $1,000 \mathrm{mg} / \mathrm{kg}$ ) and reactivation context dependent. Our results demonstrate that modulation of a reactivated memory or second experience is the combined effect of both an exogenous environmental context-dependent and an endogenous glucose-dependent memory-modulating system.
\end{abstract}

When conditions that occur during learning recur, the likelihood that the memory formed during previous learning will become reactivated or retrieved increases. The considerable empirical evidence supporting this notion is summarized in Tulving's (1974) encoding specificity principle and its extension to animals (Spear, 1976). In animal studies, effective retrieval cues include the unconditioned stimulus (US; Klein \& Spear, 1970; Richardson, Riccio, \& Mowrey, 1982), the excitatory conditioned stimulus (CS; Gordon \& Mowrer, 1980), the inhibitory CS (J. S. Miller, Jagielo, \& Spear, 1991), experimental context (Deweer, 1986; Deweer, Sara, \& Hars, 1980; Spear et al., 1980), and endogenous stimuli (Overton, 1985; Sara, 1991; for reviews see R. R. Miller, Kasprow, \& Schachtman, 1986; Spear \& Riccio, 1994). Many of these cues, including reexposure to the experimental context, also promote the reactivation of memories in human infants (Rovee-Collier, 1993) and adults (Smith, 1988).

Some theorists have argued that memory reactivation enhances the retrievability of old (unaltered) memories (Spear, 1976), whereas others have argued that reactivation provides an opportunity for new learning to occur (Gold \& McGaugh, 1975). More recently, it was suggested that

Funding for this research was supported in part by NIH-NIGMSMBRS Grants GM-418135 (to W.A.R.) and GM-08066 (to C.A.H.). Correspondence concerning this article should be addressed to W. A. Rodriguez, Departments of Psychology and Statistics, School of Science, California State University, Hayward, CA 94542 (e-mail: wrodrigu@csuhayward.edu). memory reactivation promotes retrieval-based memory strengthening (Spear \& Mueller, 1984) or old-to-new (reactivated) memory binding (Johnson \& Chalfonte, 1994). Pharmacological evidence suggests that memory retrieval consists of at least two distinct phases: (1) an early memory reactivation calcium-sensitive phase and (2) a subsequent memory-updating glutamate-sensitive phase (Summers, Crowe, \& Ng, 1995, 1996). The evidence also suggests that the cellular processes that take place during memory retrieval are similar to those that take place during memory consolidation (Przybyslawski \& Sara, 1997). Regardless of the theoretical position that one favors, investigating the effects of the context in which subsequent experiences occur is important for one's understanding the modulation of memory (Spear \& Riccio, 1994).

In the present study, we reactivated memory in three different contexts and investigated the extent to which a postreactivation injection of glucose would modulate the second experience or reactivated memory. Memory modulators include hormones, drugs, or behavioral treatments, that, depending on the conditions of administration, training, and testing, can either enhance or impair memory (McGaugh, 1990; Spear \& Riccio, 1994). Glucose modulates memories when administered shortly after training and prior to testing (Rodriguez, Horne, Mondragon, \& Phelps, 1994; for a review, see Gold, 1991; White, 1991). Glucose can also modulate recently reactivated memories (Flint \& Riccio, 1997; Rodriguez, Van Ausdle, Dhanens, \& Mondragon, 1993), and the dose-response function for these effects follows a bimodal cubic trend (Rodriguez, Horne, \& Padilla, 1999). 
The memory-modulating effects of glucose are time dependent and are not the result of proactive glucose effects (e.g., Gold, 1986; Rodriguez et al., 1993). Research with humans indicates that glucose can influence declarative memory (Gold, 1992; Korol \& Gold, 1998; Messier \& Gagnon, 1996). Although the mechanism by which glucose modulates memories is not completely understood, glucose could be an important component of the body's endogenous memory-modulating system (Gold, 1991, 1992; White, 1991), and the glucose memory system may be less efficient in the aged, in Alzheimer's patients, and in diabetics (Messier \& Gagnon, 1996). In both animals and humans, the endogenous glucose memory system may be particularly important during the storage of memories of emotionally significant events (Gold, 1992). These results suggest that the effects of glucose on memory may have important clinical implications.

In our experiments, we used a negative transfer design and interpolated reactivation treatments to investigate the effects of glucose $(100 \mathrm{mg} / \mathrm{kg}$ s.c.) on memories reactivated in various experimental contexts. Twenty-four hours after passive avoidance training, a single reactivation treatment was presented (direct reactivation procedure; Spear, 1976), and $24 \mathrm{~h}$ after the direct reactivation treatment, acquisition of an active avoidance (reversal) response was used to assess memory. There are two important features to our behavioral paradigm. First, the use of an interference design should increase experimental sensitivity because it permits a wide response range (Postman, 1972; Rodriguez et al., 1994). Second, because the reactivation and injection treatments are administered after training (i.e., $24 \mathrm{~h}$ before testing), the subjects are trained and tested under identical conditions. This ensures that the direct effects of glucose on the sensorimotor and motivational characteristics of the active avoidance task are negligible or eliminated.

Our reactivation treatments were designed to reactivate the original (old) memory with different degrees of fidelity. In Experiment 1, immediately after memory reactivation, we administered a dose of glucose $(100 \mathrm{mg} / \mathrm{kg}$ s.c.) that had been shown previously to enhance the effectiveness of memory reactivation (Rodriguez et al., 1999; Rodriguez et al., 1993). The three memory reactivation treatments that we employed, ordered according to their overlap with the conditions of training (Deweer, 1986), were (1) old experimental room with the training US (OLD + US); (2) old experimental room without the training US (OLD); and (3) new experimental room with the training US (NEW + US). On the basis of our earlier work (Rodriguez et al., 1999), we hypothesized that as the effectiveness of the memory reactivation treatment increased, the further enhancement in memory produced by glucose administration would increase. We also expected to observe context specificity and, therefore, to find that an effective reactivation treatment (e.g., the US) presented in the old context might not be effective when presented in a new room or context (Rovee-Collier, 1993).

In Experiment 2, we investigated the dose-dependent effects of glucose on memory reactivated in the old experimental room with the training US (OLD + US) and in the new experimental room with the training US (NEW + US). Previously we have shown that the doseresponse curve for the effects of glucose $(32-2,000 \mathrm{mg} / \mathrm{kg})$ on memories reactivated in the old experimental room with the training US follows a cubic trend (Rodriguez et al., 1999). On the basis of these results and the results of Experiment 1, we expected to observe that the effects of glucose $(100,320$, and $1,000 \mathrm{mg} / \mathrm{kg})$ on memory reactivated in the old experimental room with the training US, but not in the new experimental room with the training US, would follow a U-shaped curve. Furthermore, to ensure that the effects we observed were not merely proactive effects of glucose, we included glucose $(100,320$, and $1,000 \mathrm{mg} / \mathrm{kg}$ ) no-reactivation (NR) control treatments in the design of Experiment 2.

\section{EXPERIMENT 1}

\section{Method}

Subjects. The subjects were 105 male, 60-day-old SpragueDawley rats. All rats were housed individually and maintained on a 12:12-h light:dark cycle ( $0700 \mathrm{~h}$ on). Behavioral testing was conducted between 1200 and $1600 \mathrm{~h}$. Food and water access was ad lib. The Animal Care and Use Committee at New Mexico Highlands University approved all animal use and testing procedures in advance.

Apparatus. The apparatus was a one-way shuttle avoidance chamber (detailed in Rodriguez et al., 1994) that contained a translucent white and an opaque black compartment. A vertically sliding guillotine door separated the $27 \times 14.5 \times 14 \mathrm{~cm}$ compartments. A $0.5-\mathrm{mA}$ scrambled footshock (Lafayette $82404 / 5 . \mathrm{SS}$ ) could be delivered across the stainless steel floor rods. A $2-\mathrm{Hz}$ flashing light $(7.5 \mathrm{~W})$ on the outside wall of the white chamber signaled the opening of the door; the light was extinguished when the rat entered the black compartment. A wire mesh cage $(25 \times 20 \times$ $18 \mathrm{~cm}$ ) was used to transport the rats and also served as the intertrial interval (ITI) chamber. A clear Plexiglas chamber $(28 \times 21 \times$ $20 \mathrm{~cm}$ ) with a grid floor similar to that in the avoidance chamber served as the memory reactivation chamber.

Passive avoidance training and active avoidance memory testing took place in a small $(1.7 \times 4.0 \mathrm{~m})$, dimly illuminated experimental room with background white noise $(63 \mathrm{~dB})$. This same room served as the old-experimental-room memory reactivation context. A large $(6 \times 4 \mathrm{~m})$ irregularly shaped, brightly illuminated treatment room with a distinctive odor (rat food), no background white noise, and a translucent window served as the new-experimental-room memory reactivation context.

\section{Experimental Procedures}

The experiment consisted of three phases (Rodriguez et al., 1999): (1) passive avoidance training (to form the new memory); (2) exposure $24 \mathrm{~h}$ after one of three different reactivation treatments (to promote reactivation of the old passive avoidance memory); and (3) $24 \mathrm{~h}$ after, training on an active avoidance negative transfer (discrimination reversal) task (to test the rats' passive avoidance memory). On each passive avoidance trial, the rat was placed in the white 
compartment, the sliding door was opened, and, if the rat entered the black compartment (incorrect response), it received a footshock that terminated when the rat reentered the "safe" white compartment. A correct response was recorded if the rat remained in the white compartment (i.e., did not enter the black compartment) for $60 \mathrm{sec}$. After each response, the rat was placed in the ITI chamber for $30 \mathrm{sec}$. Passive avoidance training continued until the rat made three consecutive correct responses. The number of trials required to reach this criterion was used as a measure of performance.

Twenty-four hours after passive avoidance training, the rats received one of three different reactivation treatments: (1) The rat was placed in the reactivation chamber in the experimental room, and $10 \mathrm{sec}$ later a footshock $(0.5 \mathrm{~mA}, 1 \mathrm{sec})$ was delivered (old-roomwith-footshock-US reactivation [OLD+US]); (2) the rat was placed in the reactivation chamber in the old experimental room, and a footshock was not delivered (old-room reactivation [OLD]); or (3) the rat was placed in the reactivation chamber in the new experimental room, and $10 \mathrm{sec}$ later a footshock $(0.5 \mathrm{~mA}, 1 \mathrm{sec})$ was delivered [new-room-with-footshock-US reactivation (NEW+US)]. After $10 \mathrm{sec}$ in the reactivation chamber, the rat was removed and given a subcutaneous injection of either glucose $(100 \mathrm{mg} / \mathrm{kg})$ or saline Rats in the control group received NR treatment and remained in their home cages until active avoidance training was conducted.

Twenty-four hours after reactivation treatment, the rats received active avoidance negative transfer (discrimination reversal) training. At the start of each active avoidance trial, the rat was placed in the white compartment, and the sliding door was opened. If the rat entered the ("safe") black compartment within 5 sec (correct response), it did not receive a footshock. If the rat $\pi$ in the white com- partment for $5 \mathrm{sec}$ (incorrect response), it received a footshock, which terminated when the rat entered the black compartment. After each response, the rat was placed in the ITI chamber for 30 sec. Active avoidance training continued until the rat made five consecutive correct responses. The number of trials required to reach this criterion was used as a measure of performance.

\section{Injections, Design, and Data Analysis}

The rats were assigned randomly to the injection and reactivation treatments. All injections were blind coded and were delivered subcutaneously to the scruff of the neck. A $5 \%$ solution of glucose and distilled water was prepared daily. The injection volume for saline treatment was identical to that for the glucose treatment. The experimental design formed a 2 (injection: saline or glucose) $\times 3$ (reactivation treatment: OLD+US, OLD, or NEW+US) factorial, plus an NR control group that received no injection. The sample size for all groups was 15 . The number of trials to criterion for passive avoidance and active avoidance training was analyzed with analyses of variance (ANOVAs) and with separate-variance, pairwise planned comparisons. All magnitude-of-effect estimates for the pairwise comparisons focused on the specified comparison and, thus, were not influenced by the other comparisons (Huberty $\&$ Morris, 1988). A monotonic trend analysis was used to test the predicted ordering of means (Braver \& Sheets, 1993). We interpreted an increase in the number of trials required to reach criterion as an indication of enhanced retention of the passive avoidance memory, and we interpreted a decrease in the number of trials required to reach criterion on the active avoidance task as an indication of impaired retention of the passive avoidance memory. The criterion for rejection of all null hypotheses was set at $p<.05$

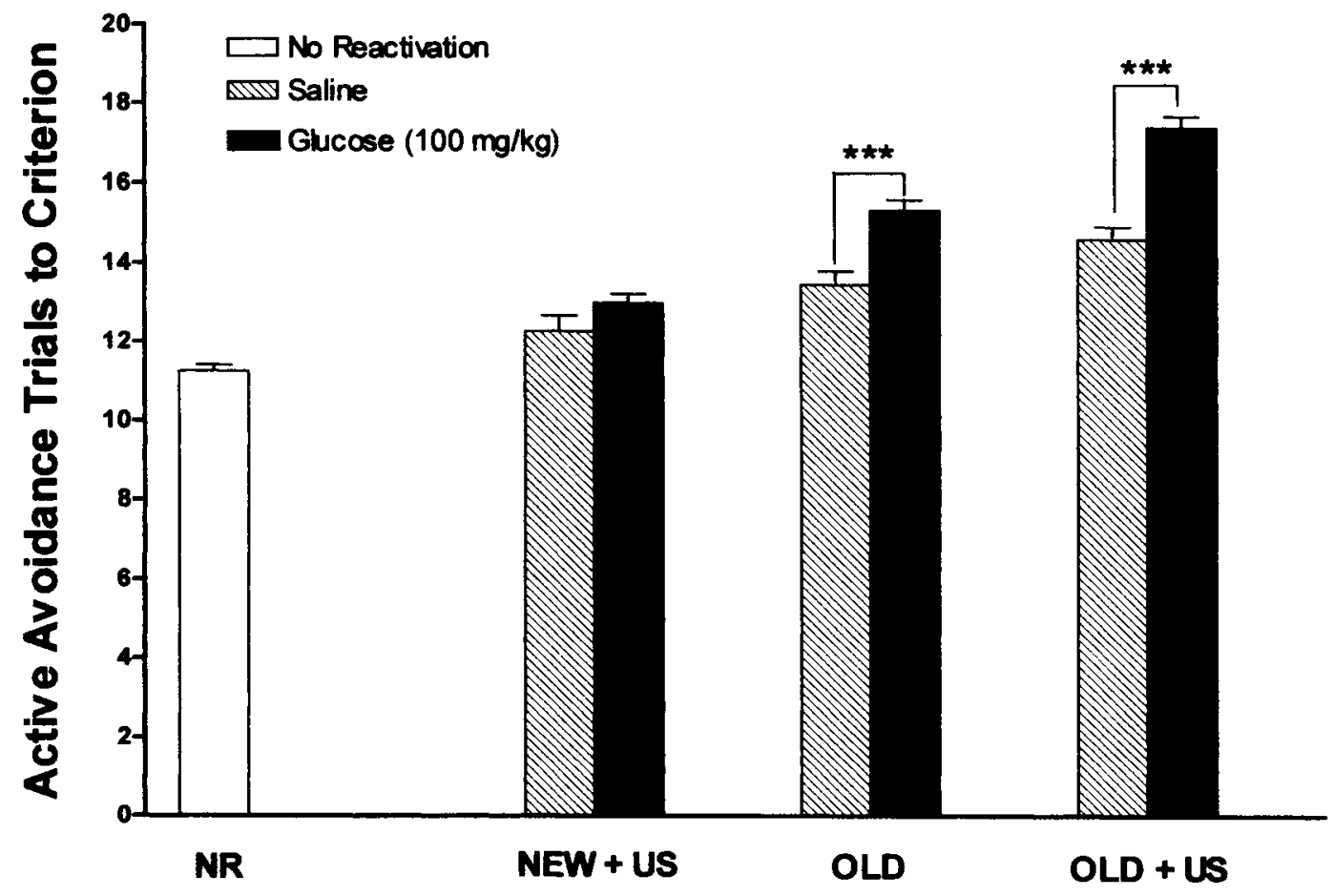

\section{Reactivation Context}

Figure 1. Effects of glucose $(100 \mathrm{mg} / \mathrm{kg} \mathrm{s.c.})$ and saline administered immediately after memory reactivation treatment (OLD+US, OLD, NEW+US; $24 \mathrm{~h}$ after acquisition of a passive avoidance response) on the acquisition (mean and standard error for trials to criterion) of an active avoidance (discrimination reversal) response. More trials required to reach criterion indicate better memory for the passive avoidance response. $\quad * * * p<.001$. 


\section{Results}

All rats reached the passive avoidance criterion very quickly ( $M=4.18)$, and no statistically significant amonggroups differences were found $(F<1.0)$. Figure 1 shows the mean number of trials required to reach criterion on the active avoidance reversal task for each group. An examination of Figure 1 indicates that in saline-treated rats, all three memory reactivation contexts enhanced memory for the passive avoidance response; that is, memory reactivation impaired acquisition of the active avoidance response as compared with acquisition in the NR control group [OLD+US, $t(20.1)=9.38, p<.001, r^{2}=.49$; OLD, $t(19.6)=5.95, p<.001, r^{2}=.30 ; \mathrm{NEW}+\mathrm{US}, t(17.9)$ $\left.=2.30, p=.03, r^{2}=.06\right]$. These results confirmed our hypothesis that reactivation in the old experimental room with footshock (US) would be the most effective reactivation treatment, followed in order by reactivation in the old experimental room without footshock and reactivation in the new experimental room with footshock [test for monotonic trend: $[F(1,42)=21.37, p<.001]$.

Importantly, glucose $(100 \mathrm{mg} / \mathrm{kg})$ further enhanced the memory of the passive avoidance response beyond that produced by memory reactivation alone in the two old, but not new, contexts [OLD+US, $t(27.7)=6.48, p<$ $.001, r^{2}=.32$; OLD, $t(26.8)=4.33, p<.001, r^{2}=.17$; $\mathrm{NEW}+\mathrm{US}, t(21.4)=1.59, p=.13, r^{2}=.03$ ]. Figure 1 shows that the greater the reactivation effect, the greater the glucose effect on memory modulation. The statistically significant interaction confirms that the effects of glucose on a reactivated memory increase as the effectiveness of the memory reactivation treatment increases $[F(2,84)=5.48, p<.01]$. The main effects for injection and reactivation treatment were significant, and the magnitudes of both of these effects were substantial $[F(1,84)=$ $\left.49.7, p<.001, r^{2}=.19 ; F(2,84)=58.0, p<.001, r^{2}=.44\right]$.

\section{EXPERIMENT 2}

\section{Method}

The subjects were 120 experimentally naive rats. The apparatus and experimental procedures used in Experiment 2 were identical to those used in Experiment 1, with the following exceptions. Twenty-four hours after passive avoidance training (i.e., $24 \mathrm{~h}$ before active avoidance training), the rats received one of two reactivation treatments tested in Experiment 1. Either the rat was placed in the reactivation chamber in the experimental room, and $10 \mathrm{sec}$ later a footshock $(0.5 \mathrm{~mA}, 1 \mathrm{sec})$ was delivered [old-room-withfootshock-US reactivation (OLD+US)] or the rat was placed in the reactivation chamber in the new experimental room, and $10 \mathrm{sec}$ later a footshock $(0.5 \mathrm{~mA}, 1 \mathrm{sec})$ was delivered [new-room-withfootshock-US reactivation (NEW+US)]. After $10 \mathrm{sec}$ in the reactivation chamber, the rat was removed and given a subcutaneous injection of glucose $(100,320$, or $1,000 \mathrm{mg} / \mathrm{kg})$. Four control groups of rats received NR treatment, but were administered either glucose $(100,320$, or $1,000 \mathrm{mg} / \mathrm{kg})$ or saline in the colony room $24 \mathrm{~h}$ after passive avoidance training (i.e., $24 \mathrm{~h}$ before active avoidance testing). The experimental design formed a 3 (glucose: 100, 320, or $1,000 \mathrm{mg} / \mathrm{kg}$ ) $\times 3$ (reactivation context: OLD+US, NEW+US, or NR) factorial, plus an isolated saline NR control. The sample size in each of the 10 groups was 12 . BMDP $4 \mathrm{~V}$ was used to calculate the orthogonal polynomial interaction contrast effects.

\section{Results}

The 10 groups did not differ statistically on the number of trials to criterion on the passive avoidance task $[M=4.2, S D=.58 ; F(9,110)=.60, p=.79]$. This result indicates that, prior to the experimental treatments, there were no reliable differences among the groups.

Figure 2 is a plot of the mean number of trials to criterion for each of the 10 groups on the active avoidance reversal task. A one-way ANOVA conducted on the four NR control groups (glucose: $100,320,1,000 \mathrm{mg} / \mathrm{kg}$; saline) was not statistically significant $(F<1.0)$. This result indicates that in the absence of a reactivation treatment, injecting rats with glucose in the colony room does not affect their memory for the passive avoidance task. The memory-enhancing effect of the NEW + US reactivation treatment was confirmed, given that a statistically significant two-way ANOVA main effect for reactivation treatment was found [NEW + US vs. NR: $F(1,66)=4.54$; $p=.04]$, whereas the interaction between reactivation treatment and the dose of glucose administered (100,320, or $1,000 \mathrm{mg} / \mathrm{kg}$ ) was not found to be statistically significant $(F<1.0)$.

The effects of glucose $(100,320$, or $1,000 \mathrm{mg} / \mathrm{kg})$ administered in the OLD + US context on reactivated memory followed a quadratic trend $[F(1,33)=7.94, p=$ $\left..008, r_{\text {quad }}^{2}=.81\right]$. There was no statistically significant effect of the dose of glucose administered in the NEW + US reactivation context on memory $[F(1,33)=.79, p=$ $.92]$. That the two dose-response curves were distinct from each other was confirmed by the statistically significant dose $e_{\text {quadratic }} \times$ reactivation context interaction contrast $\left[F(1,66)=3.98, p=.05, r^{2}\right.$ quad $\left.=.99\right]$. Pairwise contrasts between the OLD + US and NEW + US reactivation treatment contexts at each glucose dose level showed that 100 and $1,000 \mathrm{mg} / \mathrm{kg}$, but not $320 \mathrm{mg} / \mathrm{kg}$, of glucose enhanced memory when it was administered in the OLD + US reactivation context $[t(21.8)=2.19, p=$ $.04, r^{2}=.18 ; t(21.6)=2.08, p=.05, r^{2}=.17 ; t(22.0)=$ $.18, p=.86]$, respectively. Together these results confirm our prediction that the effects of glucose $(100,320$, and $1,000 \mathrm{mg} / \mathrm{kg}$ ) on memory reactivated in the old experimental room with the training US, but not in the new experimental room with the training US, would follow a U-shaped curve.

\section{DISCUSSION}

The primary purpose of the present studies was to investigate the relationship between the effectiveness of memory reactivation treatment or second experience and the magnitude of the effect of glucose on memory modulation. In accordance with our hypothesis, we observed in Experiments 1 and 2 a direct relationship between the 


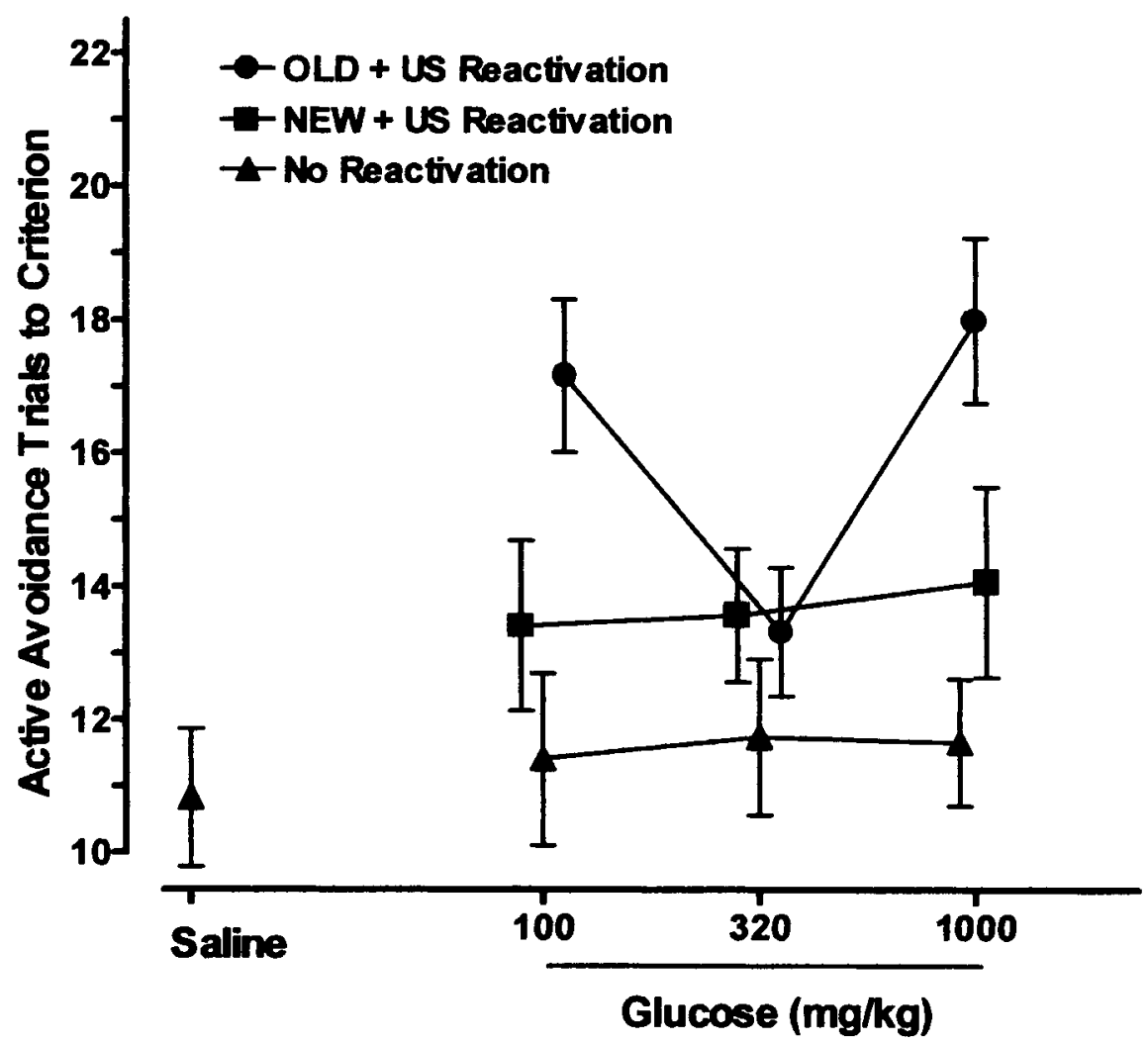

Figure 2. Effects of glucose $(100,320$, and $1,000 \mathrm{mg} / \mathrm{kg}$ s.c.) administered immediately after memory reactivation treatment (OLD+US, NEW+US; $24 \mathrm{~h}$ after acquisition of a passive avoidance response) on the acquisition (mean and standard error for trials to criterion) of an active avoidance (discrimination reversal) response.

magnitude of the memory-reactivation effect and the magnitude of the glucose memory-enhancement effect. The effects of glucose on a reactivated memory were found to depend on the comprehensiveness of the context in which memory reactivation occurred. When the memory-reactivation context was limited, the ability of postreactivation glucose administration to modulate further the reactivated memory was also limited, whereas when the fidelity of the reactivated memory increased, the ability of glucose to modulate that memory increased.

The three reactivation treatments tested all impaired subsequent learning of the active avoidance (reversal) response; that is, all treatments improved memory for the old passive avoidance response. These results replicate the reports of others that the environmental context (Deweer, 1986; Deweer et al., 1980; Spear et al., 1980) and the US (Klein \& Spear, 1970; Richardson et al., 1982) are effective reactivation treatments.

The reactivation treatments or second experiences we employed were designed to reactivate the original (old) memory with different degrees of effectiveness. Memory reactivation in the old experimental room with footshock (US) delivery was the most effective reactivation treatment, followed in order by reactivation in the old experimental room and reactivation in the new experi- mental room with footshock delivery. Not only are these memory-reactivation effects orderly, but the magnitudeof-effect estimates indicate that they are substantial. The memory-reactivation effects we report here are consistent with the notion that as the overlap between the conditions of learning and the conditions of reactivation increases, the degree of memory reactivation (or the fidelity of the memory) also increases. Memories reactivated with greater fidelity might be better able to promote retrieval-based memory strengthening (Spear \& Mueller, 1984), old-to-new memory binding (Johnson \& Chalfonte, 1994), or new learning for the second experience (Gold \& McGaugh, 1975). A possible neurobiological mechanism for the effects we observed might include adjustments in the pathways between the neocortex and hippocampal system (McClelland, McNaughton, \& O'Reilly, 1995).

We hypothesized that glucose would only modulate memory when reactivation took place in the original context (reactivation-context-specificity effect). In Experiments 1 and 2, glucose did not significantly modulate memory when administered after reactivation in the new context. Although in the present studies we found that reactivation in the old experimental room was more effective than reactivation in the new experimental room 
with US delivery, this effect is likely to be a function of the specific conditions of training, reactivation, and testing that were employed, since the opposite effect also has been reported (Klein \& Spear, 1970).

The dose-response curve for the effects of glucose $(100,320$, and $1,000 \mathrm{mg} / \mathrm{kg})$ on memory reactivation in the OLD + US context was U-shaped, which replicates our previous findings (Rodriguez et al., 1999). Because we did not find an effect of glucose on memory when glucose was administered in the colony room $24 \mathrm{~h}$ after passive training (i.e., $24 \mathrm{~h}$ before active avoidance testing), the dose-dependent memory modulating effects that we report here are likely not due to general proactive glucose effects. Rather, these memory effects probably depend on the fidelity of the reactivated memory at the time that glucose is administered.

Understanding the conditions that enable reactivated memories to become stronger or more vivid has important clinical (Loftus, 1992) and theoretical (Johnson \& Chalfonte, 1994; Rovee-Collier, 1993; Spear \& Riccio, 1994) implications. The present experiments show that a postreactivation injection of glucose, an agent that is believed to be an integral part of the body's endogenous emotional memory modulation system, interacts with the reactivation context to improve memory further. Similar to naturally occurring, emotionally arousing events (Christianson, 1992), postreactivation glucose injection would also not be expected to improve memory under all conditions. The results of our experiments are consistent with this theoretical expectation.

The present results could have implications for our understanding the strengthening of memories that occurs when memories are reactivated or recovered in clinical situations. Our results suggest that there is a synergistic relationship between the environmental and emotional contexts in which a memory is reactivated and that the ability of other contemporaneous emotion-generating events (that can be mimicked experimentally by glucose administration) further strengthens the reactivated memory.

Our present results support the following conclusions: (1) As the overlap between the cues present during learning and the cues present during memory reactivation increases, the magnitude of the effect of the memory reactivation treatment increases. (2) Postreactivation glucose administration modulates (enhances) memory beyond that produced by memory reactivation alone. This relationship follows a monotonic trend: As the magnitude of the memory-reactivation effect increases, the magnitude of the glucose memory-reactivation modulation effect increases. (3) The effects of glucose on a reactivated memory depend on both the context in which memory reactivation occurs (and thus the fidelity of the memory) and the dose of glucose administered.

\section{REFERENCES}

Braver, S. L., \& SheEts, V. L. (1993). Monotonic hypotheses in multiple group designs: A Monte Carlo study. Psychological Bulletin, 113, 379-395.
Christianson, S. A. (1992). Emotional stress and eyewitness memory: A critical review. Psychological Review, 112, 284-309.

Deweer, B. (1986). Pretest cuing after forgetting of a food-motivated maze task in rats: Synergistic action of context and reinforcement. Animal Learning \& Behavior, 14, 249-256.

Deweer, B., SARA, S. J., \& HARS, B. (1980). Contextual cues and memory retrieval in rats: Alleviation of forgetting by a pretest exposure to background stimuli. Animal Learning \& Behavior, 8, 265-272.

Flint, R. W., \& Riccio, D. C. (1997). Pretest administration of glucose attenuates infantile amnesia for passive avoidance conditioning in rats. Developmental Psychobiology, 31, 207-216.

GoLD, P. E. (1986). Glucose modulation of memory storage processing. Behavioral \& Neural Biology, 45, 342-349.

GoLD, P. E. (1991). An integrated memory regulation system: From blood to brain. In R. C. A. Frederickson, J. L. McGaugh, \& D. L. Felten (Eds.), Peripheral signaling of the brain: Role in neural-immune interactions and learning and memory (pp. 391-419). Toronto: Hogrefe \& Huber.

GoLD, P. E. (1992). A proposed neurobiological basis for regulating memory storage for significant events. In E. Winograd \& U. Neisser (Eds.), Affect and accuracy in recall: Studies of "flashbulb" memories (pp. 141-161). Cambridge: Cambridge University Press.

Gold, P. E., \& MCGaugh, J. L. (1975). A single-trace, two process view of memory storage processes. In D. Deutsch \& J. A. Deutsch (Eds.), Short-term memory (pp. 355-390). New York: Academic Press.

GoRdon, W. C., \& MOWRER, R. R. (1980). An extinction trial as a reminder treatment following electroconvulsive shock. Animal Learning \& Behavior, 8, 363-367.

HuberTy, C. J., \& Morris, J. D. (1988). A single contrast test procedure. Educational \& Psychological Measurement, 48, 567-578.

Johnson, M. K., \& Chalfonte, B. L. (1994). Binding complex memories: The role of reactivation and the hippocampus. In D. L. Schacter \& E. Tulving (Eds.), Memory systems 1994 (pp. $311-350$ ). Cambridge, MA: MIT Press.

KLEIN, S. B., \& SPEAR, N. E. (1970). Reactivation of avoidance learning memory in the rat after intermediate retention intervals. Journal of Comparative \& Physiological Psychology, 72, 498-504.

KOROL, D. L., \& GolD, P. E. (1998). Glucose, memory, and aging. American Journal of Clinical Nutrition, 67, 764S-771S.

LofTus, E. F. (1992). When a lie becomes memory's truth: Memory distortion after exposure to misinformation. Current Directions in $P_{s y-}$ chological Science, 1, 121-123.

MCClelland, J. L., MCNaughton. B. L.. \& O'Reilly, R. C. (1995) Why there are complementary learning systems in the hippocampus and neocortex: Insights from the successes and failures of connectionist models of learning and memory. Psychological Review, 102. 419-457.

McGaugh, J. L. (1990). Significance and remembrance: The role of neuromodulatory systems. Psychological Science, 1, 15-25.

Messier, C., \& GAGNon. M. (1996). Glucose regulation and cognitive functions: Relation to Alzheimer's disease and diabetes. Behavioural Brain Research, 75, 1-10.

Miller, J. S., Jagielo, J. A., \& Spear, N. E. (1991). Alleviation of short-term forgetting: Effects of the $\mathrm{CS}$ and other conditioning elements in prior cueing or as context during test. Learning \& Motivation, 21, 96-109.

Miller, R. R., Kasprow, W. J., \& Schachtman, T. R. (1986). Retrieval variability: Sources and consequences. American Journal of Psychologv, 99, 145-218.

Overton, D. A. (1985). Contextual stimulus effects of drugs and internal states. In P. D. Balsam \& A. Tomie (Eds.), Context and learning (pp. 357-384). Hillsdale NJ: Erlbaum.

Postman, L. (1972). Transfer, interference and forgetting. In J. W. Kling \& L. A. Riggs (Eds.), Woodworth \& Schlosberg's Experimental psychology: Vol. II. Learning, motivation, and memory (pp. 1019-1132). New York: Holt, Rinehart \& Winston.

Przybyslawski, J., \& Sara, S. J. (1997). Reconsolidation of memory after its reactivation. Behavioural Brain Research, 84, 241-246.

Richardson, R., Riccio, D. C., \& Mowrey, H. ( 1982). Retrograde amnesia for previously acquired Pavlovian conditioning: UCS exposure as a reactivation treatment. Physiological Psychology, 10, 384-390. 
Rodriguez, W. A., Horne, C. A., Mondragon, A. N., \& Phelps, D. D. (1994). Comparable dose-response functions for the effects of glucose and fructose on memory. Behavioral \& Neural Biology, 61, 162169.

Rodriguez, W. A., Horne, C. A., \& Padilla J. L. (1999). Effects of glucose and fructose on recently reactivated and recently acquired memories. Progress in Neuro-Psychopharmacology \& Biological Psychiatry, 23, 1285-1317.

Rodriguez, W. A., Van Ausdle, L. R., Dhanens, K., \& Mondragon, A. N. (1993). Glucose modulates recently reactivated memories. Psychobiology, 21, 93-100.

ROVEE-COLLIER, C. (1993). The capacity for long-term memory in infancy. Current Directions in Psychological Science, 2, 130-135.

SARA, S. J. (1991). Neuromodulatory influences on retrieval. In J. Weinman \& J. Hunter (Eds.), Memory: Neurochemical and abnormal perspectives (pp. 105-128). New York: Hardwood Academic.

Sмiтн, S. M. (1988). Environmental context-dependent memory. In G. M. Davies \& D. M. Thomson (Eds.), Memory in context: Context in memory (pp. 13-34). New York: Wiley.

SPEAR, N. E. (1976). Retrieval of memory: A psychobiological approach. In W. K. Estes (Ed.), Handbook of learning and cognitive processes: Vol. 4. Memory processes (pp. 17-90). Hillsdale, NJ: Erlbaum.

Spear, N. E., \& Mueller, N. E. (1984). Consolidation as a function of retrieval. In H. Weingartner \& E. S. Parker (Eds.), Memory consoli- dation: Psychobiology of cognition (pp. 111-147). Hillsdale, NJ: Erlbaum.

SPEAR, N. E., \& Riccio, D. C. (1994). Memory: Phenomena and principles. Boston: Allyn \& Bacon.

Spear, N. E., Smith, G. J., Bryan, R. G., Gordon, W. C., Timmons, R., $\&$ ChISZAR, D. A. (1980). Contextual influences on the interaction between conflicting memories in the rat. Animal Learning \& Behavior, 8, 273-281.

Summers, M. J., Crowe, S. F., \& NG, K. T. (1995). Administration of glutamate following a reminder induces transient memory loss in day-old chicks. Cognitive Brain Research, 3, 1-8.

Summers, M. J., Crowe, S. F., \& NG, K. T. (1996). Administration of lanthanum chloride following a reminder induces transient memory loss in day-old chicks. Cognitive Brain Research, 4, 109-119.

Tulving, E. (1974). Cue-dependent forgetting. American Scientist, 62 74-82.

White, N. M. (1991). Peripheral and central memory-enhancing actions of glucose. In R. C. A. Frederickson, J. L. McGaugh, \& D. L. Felten (Eds.), Peripheral signaling of the brain: Role in neuralimmune interactions and learning and memory (pp. 421-441). Toronto: Hogrefe \& Huber.

(Manuscript received April 12, 2000; revision accepted for publication October 16, 2000.) 